\title{
Effect of $n-3$ fatty acids on metabolism of apoB100-containing lipoprotein in type 2 diabetic subjects
}

\author{
K. Ouguerram ${ }^{1,2 *}$, C. Maugeais ${ }^{3}$, J. Gardette ${ }^{4}$, T. Magot $^{1,2}$ and M. Krempf ${ }^{1}$ \\ ${ }^{1}$ INSERM U539, Hôtel Dieu, Nantes, France \\ ${ }^{2}$ Facultés de Sciences et Techniques de Nantes, Nantes, France \\ ${ }^{3}$ F. Hoffmann-La Roche Ltd Pharmaceuticals, Division of Metabolic Diseases, PRBD-M Building, Basel, Switzerland \\ ${ }^{4}$ Pierre Fabre Santé, Castres, France
}

(Received 16 November 2005 - Revised 9 March 2006 - Accepted 14 March 2006)

\begin{abstract}
The effect of long-chain $n$-3 PUFA on the metabolism of apoB100-containing lipoprotein in diabetic subjects is not fully understood. The objective of the present study was to determine the effect of a daily intake of $1080 \mathrm{mg}$ EPA and $720 \mathrm{mg}$ DHA for diabetic subjects on the kinetics of apoB100-containing lipoprotein in the fasting state. A kinetic study was undertaken to determine the mechanisms involved in the effects of $n-3$ fatty acids in terms of a decrease in triacylglycerol level in type 2 diabetic patients. We have studied the effect of fish oils on the metabolism of apoB100 endogenously labelled by [5,5,5-2H3]-leucine in type 2 diabetic patients in the fasting state. The kinetic parameters of apoB100 in VLDL, intermediate-density lipoprotein and LDL were determined by compartmental modelling in five diabetic subjects before and 8 weeks after $n$-3 fatty acid treatment. Treatment did not change the plasma cholesterol level (0.801 (SD 0.120) v. 0.793 (SD 0.163 ) mmol/l) but lowered the plasma triacylglycerol level (1.776 (SD 0.280) v.1.356 (SD 0.595) $\mathrm{mmol} / \mathrm{l} ; P<0.05$ ). Treated patients showed a decrease in VLDL apoB100 concentration (0.366 (SD 0.030) v.0.174 (SD 0.036) g/l; $P<0.05$ ) related to a decrease in VLDL 1 production (1.49 (SD 0.23) v.0.44 (SD 0.19) $\mathrm{mg} / \mathrm{kg}$ per h; $P<0.05$ ) and an increase in the VLDL conversion rate (0.031 (SD 0.024) v.0.052 (SD 0.040) per h; $P<0.05$ ), with no change in fractional catabolic rates. Treatment led to a higher direct production of intermediate-density lipoprotein (0.02 (SD 0.01) v.0.24 (SD 0.12$) \mathrm{mg} / \mathrm{kg}$ per h; $P<0.05$ ). In conclusion, the present study, conducted in the fasting state, showed that supplementation with $n-3$ fatty acids in type 2 diabetic patients induced beneficial changes in the metabolism of apoB100-containing lipoprotein.
\end{abstract}

n-3 fatty acids: apoB100: Kinetic analysis: Modelling: Diabetes

The relationship between increased plasma cholesterol concentration and the development of atherosclerosis has been demonstrated in many studies (Kannel et al. 1971). Although the role of hypertriacylglycerolaemia has been controversial, it is now accepted as a risk factor for CHD (Zilversmit, 1979; Austin \& Hokanson, 1994). This atherogenic pathway involves the uptake of triacylglycerol-rich lipoprotein (Fielding et al. 1979; Gianturco et al. 1980) by the apoB48 receptor of macrophages (Brown et al. 2000), leading to their rapid conversion into foam cells.

Hypertriacylglycerolaemia is frequently associated with type 2 diabetes and could contribute to the strong development of atherosclerosis in this disease (Goldberg, 2001). Previous studies have already underlined that the insulin resistance observed in type 2 diabetes is associated with an overproduction of apoB100-containing lipoproteins and reduced LDL and VLDL catabolism (Duvillard et al. 2000; Ouguerram et al. 2003).

Epidemiological studies in Inuits have suggested that marine oils rich in $n-3$ fatty acids are hypolipidaemic and anti-atherogenic (Kromann \& Green, 1980). In addition to their anti-inflammatory, vasodilatory and antihypertensive effects (Lichtenstein et al. 1998), n-3 fatty acids are able to decrease triacylglycerol levels in animals (Harris, 1996) and human subjects (Connor et al. 1993; Harris, 1996). The effect on LDL cholesterol is more controversial depending on the dose used, the duration of treatment and the disease (Farmer et al. 2001).

Numerous in vivo kinetic studies in healthy human subjects (Connor et al. 1993) and animals (Harris, 1996) have shown that this effect is associated with a decrease in VLDL apoB100 concentration related to a reduction in production. As in normolipidaemic subjects, the $n-3$ fatty acids in diabetic patients lead to a lower plasma triacylglycerol level, but the underlying mechanisms are not fully understood.

A study involving five type 2 diabetic patients was performed by Fisher et al. (1998) on apoB100-containing lipoproteins and reported that the response to $n-3$ fatty acids was mainly a decrease in VLDL apoB100 secretion and an increase in intermediate-density lipoprotein (IDL) and LDL production. In that study, the increase in LDL production with no change of fractional catabolic rate led to an increase in LDL mass. However, 
the study was conducted in feeding subjects, which implies a possible acute effect of $n$-3-rich chylomicrons and their remnants on apoB100 metabolism (Zheng et al. 2001; Maldonado et al. 2003). Moreover, in that study (Fisher et al. 1998), the authors only compared the effect of $n-3$ to $n-6$ fatty acids, two acids known to influence lipid homeostasis (Mekki et al. 2002; Zheng et al. 2002). Such a comparison could mask some specific effects of $n-3$ fatty acids.

The purpose of the present study was to investigate the effect of fish oils on the metabolism of apoB100 in type 2 diabetic patients. This study was conducted in the fasting state to avoid the acute influence of chylomicrons and their remnants on apoB100 metabolism.

\section{Methods}

\section{Subjects}

Five patients with type 2 diabetes and dyslipidaemia (Table 1) were included in the study. Insulin treatment was an exclusion criterion. They had not been taking any medication that could affect carbohydrate or lipid metabolism for at least 1 month before the study. Patients had been treated with either sulphonylureas or biguanides for at least 3 months and were instructed by a dietitian to follow a weight-maintenance diet, (composed of (\% energy): carbohydrate 45; fat 35; protein 20) for at least 1 week prior to the study. Insulin resistance was assessed by the insulin sensitivity index (homeostasis model assessment; Matthews et al. 1985). The experimental protocol was approved by the ethical committee of Nantes University Hospital, and written informed consent was obtained before the study was started.

\section{Experimental protocol}

Five diabetic patients underwent a basal kinetic study the day before the start of the treatment. They then received six capsules/d MaxEPA (Pierre Fabre Santé, Castres, France), a concentrate of $n-3$, long-chain PUFA from fish oil, over 8 weeks. Each MaxEPA capsule contained $1000 \mathrm{mg}$ methyl ester fatty acids, providing $180 \mathrm{mg}$ EPA (20:5- $\omega 3), 120 \mathrm{mg}$ DHA (22: 6- $\omega 3)$ and $1.75 \mathrm{mg} \alpha$-tocopherol acetate. The second kinetic study was carried out at the end of the treatment.

The kinetic protocol was similar to that previously described (Ouguerram et al. 2003). Briefly, the endogenous labelling of apoB100 was carried out by constant infusion of [5,5,5-2H3]-leucine in subjects fasted overnight for $12 \mathrm{~h}$ prior to the study who remained fasting during the entire procedure. Each subject received intravenously a prime of $10 \mu \mathrm{mol} / \mathrm{kg}$ tracer immediately followed by a constant tracer infusion $(10 \mu \mathrm{mol} / \mathrm{kg}$ per $\mathrm{h})$ for $14 \mathrm{~h}$. Venous blood samples were drawn into EDTA tubes (Venoject, Paris, France) at baseline and at 15, 30 and $45 \mathrm{~min}, 1,1.5,2$ and $2.5 \mathrm{~h}$, and then hourly until $14 \mathrm{~h}$. Sodium azide, an inhibitor of bacterial growth, and Pefabloc SC (Interchim, Montluçon, France), a protease inhibitor, were added to blood samples at a final concentration of 1.5 and $0.5 \mathrm{mmol} / \mathrm{l}$, respectively.

\section{Analytical procedures}

Isolation and measurement of enrichment of lipoprotein containing apoB100. Isolation of lipoproteins and measurement of leucine enrichment in apoB 100 have previously been described (Ouguerram et al. 2003). Briefly, lipoproteins were separated by density-gradient ultracentrifugation, and apoB100 was isolated by sodium dodecylsulfate polyacrylamide gel electrophoresis. Apo bands were dried under a vacuum and then hydrolysed. The amino acids were purified by cation-exchange chromatography and then esterified and derivatised. Electron-impact GC-MS was performed on a 5891 A gas chromatograph connected with a 5971 A quadrupole mass spectrometer (Hewlett Packard Co., Palo Alto, CA, USA). The isotopic ratio was determined by selected ionmonitoring at $\mathrm{m} / \mathrm{z}$ of 282 and 285 . Calculations of apoB100 kinetic parameters were based on the tracer:tracee mass ratio (Cobelli et al. 1992).

Table 1. Clinical characteristics of type 2 diabetic patients before (base) and after (post) supplementation with MaxEPA (Pierre Fabre Santé, Castres, France)

\begin{tabular}{|c|c|c|c|c|c|c|c|c|c|}
\hline \multicolumn{2}{|c|}{ Subject } & $\frac{\text { Age (years) }}{37}$ & $\frac{\text { BMI }\left(\mathrm{kg} / \mathrm{m}^{2}\right)}{32 \cdot 2}$ & $\frac{\mathrm{HbA}_{1 \mathrm{c}}(\%)}{6 \cdot 1}$ & $\frac{\text { Insulin MU/I }}{16 \cdot 4}$ & $\begin{array}{c}\begin{array}{c}\text { Glucose } \\
(\mathrm{mmol} / \mathrm{l})\end{array} \\
8.7\end{array}$ & $\begin{array}{c}\begin{array}{c}\text { Homeostasis model } \\
\text { assessment }\end{array} \\
6.3\end{array}$ & $\begin{array}{c}\begin{array}{c}\text { Plasma cholesterol } \\
(\mathrm{mmol} / \mathrm{l})\end{array} \\
0.820\end{array}$ & $\begin{array}{c}\text { Plasma } \\
\begin{array}{c}\text { triacylglycerol } \\
(\mathrm{mmol} / \mathrm{l})\end{array} \\
1.873\end{array}$ \\
\hline & Post & & $30 \cdot 1$ & $5 \cdot 2$ & 6.5 & $6 \cdot 1$ & $1 \cdot 8$ & 0.615 & 0.630 \\
\hline \multirow[t]{2}{*}{2} & Base & 54 & $31 \cdot 8$ & $5 \cdot 2$ & ND & $7 \cdot 1$ & ND & 0.789 & 1.628 \\
\hline & Post & & $32 \cdot 4$ & $5 \cdot 6$ & ND & $7 \cdot 6$ & ND & 0.828 & 1.549 \\
\hline 3 & Base & 55 & $26 \cdot 6$ & $5 \cdot 1$ & $26 \cdot 9$ & $7 \cdot 7$ & $9 \cdot 2$ & 0.971 & 1.689 \\
\hline \multirow[t]{2}{*}{4} & Base & 36 & $33 \cdot 3$ & $8 \cdot 7$ & $12 \cdot 0$ & $13 \cdot 0$ & $6 \cdot 9$ & 0.639 & 1.470 \\
\hline & Post & & 32.9 & $9 \cdot 1$ & $15 \cdot 1$ & $13 \cdot 3$ & 8.9 & 0.662 & $1 \cdot 120$ \\
\hline \multirow[t]{2}{*}{5} & Base & 65 & $29 \cdot 0$ & $11 \cdot 1$ & $17 \cdot 8$ & $11 \cdot 3$ & 8.9 & 0.782 & $2 \cdot 205$ \\
\hline & Post & & $28 \cdot 6$ & $8 \cdot 6$ & $17 \cdot 9$ & $10 \cdot 5$ & $8 \cdot 3$ & 1.022 & $2 \cdot 240$ \\
\hline \multicolumn{2}{|c|}{ Mean base } & 49 & 30.6 & $7 \cdot 2$ & $18 \cdot 3$ & 9.5 & $7 \cdot 8$ & 0.801 & 1.776 \\
\hline \multicolumn{2}{|c|}{ SD } & 13 & $2 \cdot 7$ & $2 \cdot 6$ & $6 \cdot 3$ & 2.5 & 1.4 & 0.120 & 0.280 \\
\hline \multicolumn{2}{|c|}{ Mean post } & - & $30 \cdot 2$ & 6.9 & $15 \cdot 4$ & 8.9 & 6.5 & 0.793 & $1.356^{*}$ \\
\hline \multicolumn{2}{|r|}{ SD } & - & 2.5 & 1.8 & $6 \cdot 6$ & $3 \cdot 0$ & $3 \cdot 2$ & 0.163 & 0.595 \\
\hline
\end{tabular}

$\mathrm{ND}$, not determined.

${ }^{*} P<0.05$, post $v$. base.

For details of subjects and procedures, see this page. 
Measurements of lipids and apoB100. Cholesterol and triacylglycerol concentrations were measured using commercially available enzymatic kits (Boehringer Mannheim $\mathrm{GmbH}$, Mannheim, Germany) at three different sampling times. ApoB100 concentrations were obtained in lipoprotein fractions by combining selective precipitation and MS (Beghin et al. 2000). The percentage recovery of cholesterol, triacylglycerol and apoB100 after centrifugation was higher than 85 .

Modelling. Kinetic analysis of tracer:tracee ratios was achieved using computer software for simulation, analysis and modelling. The model used (Fig. 1) is the same as that previously developed for apoB100 metabolism in diabetic patients (Ouguerram et al. 2003). This model takes into account heterogeneity in VLDL. In this model, a forcing function, corresponding to the time course of plasma leucine enrichment, was used to drive the appearance of leucine tracer in the apoB 100 of the different lipoprotein fractions.

ApoB100 enters into plasma through VLDL secretion and the direct production of IDL and LDL. Direct removal of apoB100 occurs from VLDL1 $(\mathrm{k}(0,10))$, VLDL2 $(\mathrm{k}(0,20))$, VLDL remnant (VLDLR) $(\mathrm{k}(0,11))$, IDL $(\mathrm{k}(0,30))$ and LDL $(\mathrm{k}(0,40))$. ApoB100 transfer to higher-density lipoproteins occurs by conversion for VLDL1 $(\mathrm{k}(20,10)$, $\mathrm{k}(11,10))$, VLDL2 $(\mathrm{k}(30,20), \mathrm{k}(40,20))$ and IDL $(\mathrm{k}(40,30))$. The methods provided identified values and standard deviations as obtained by iterative least squares fitting for individual kinetic parameters. Standards deviations were less than $30 \%$ for most of the parameters (data not shown). The use of more complex models did not provide a significant improvement in the fitting from the $F$ test and Akaike information criterion (Pont et al. 1998).

For comparison between the two states (before and after $n-3$ treatment), the VLDL1, VLDL2 and VLDLR data were presented as the VLDL conversion rate and VLDL direct removal rate. The VLDL conversion rate was calculated as VLDL2 conversion flux divided by total VLDL mass. The direct removal of VLDL was calculated as the flux of VLDL1, VLDL2 and VLDLR direct removal divided by the total VLDL mass (Ouguerram et al. 2003). The VLDL fractional catabolic rate represented the sum of the conversion and direct removal rates.

As all our patients were obese, pools of apoB100 in the plasma or in VLDL, IDL and LDL were calculated by multiplying the apoB100 concentration by $0.037(1 / \mathrm{kg})$, assuming a plasma volume of $3.7 \%$ of body weight (Dagher et al. 1965). The apoB 100 production rate in $\mathrm{mg} / \mathrm{kg}$ per $\mathrm{h}$ represented the product of fractional catabolic rate and pool size of apoB100 in the lipoprotein fractions.

Statistical analysis. Results are reported as means and standard deviations. Wilcoxon's signed rank-test, performed with Statview F-4.5 (Abacus Concept, Berkeley, CA, USA) was used to compare data before and after treatment. A twotailed probability level of 0.05 or less was accepted as statistically significant.

\section{Results}

Concentrations of lipids and apoB100 in plasma and in lipoprotein fractions are shown in Tables 1 and 2 before and after $n-3$ administration. Compared with the basal state, a lower concentration of plasma triacylglycerol (1.776 (SD 0.280 ) $\mathrm{mmol} / \mathrm{l}$ v. 1.356 (SD 0.595) $\mathrm{mmol} / \mathrm{l} ; P<0.05$ ) was observed. This decrease was related to a fall in VLDL1 triacylglycerol (1.006 (SD 0.271) mmol/l v. 0.534 (SD 0.289) $\mathrm{mmol} / \mathrm{l} ; \quad P<0.05)$. Treatment did not significantly affect plasma total cholesterol. A decrease of apoB100 in VLDL (0.366 (SD 0.030) v. 0.174 (SD 0.036) g/l; $P<0.005)$ related to a fall in VLDL1 apoB $(0.244$ (SD 0.015) $v$. 0.075 (sD 0.050$) \mathrm{g} / \mathrm{l} ; \quad P<0.005$ ) was observed with treatment.

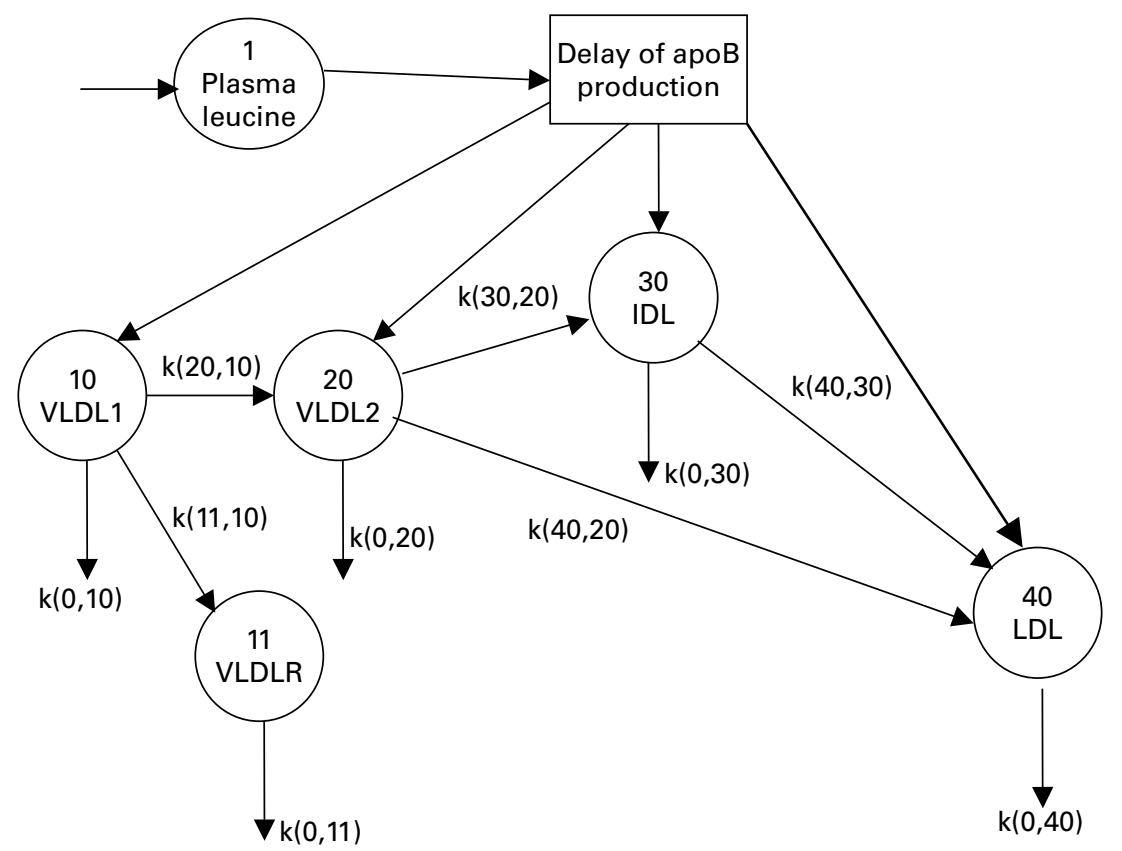

Fig. 1. Model of apoB100-containing lipoprotein metabolism. For details of subjects and procedures, see p. 101. IDL, intermediate-density lipoprotein; VLDLR; very low-density lipoprotein $\mathrm{R}$. 
Table 2. Lipoprotein composition in diabetic subjects before and during treatment with MaxEPA (Pierre Fabre Santé, Castres, France)

\begin{tabular}{|c|c|c|c|c|c|c|c|c|c|c|c|c|}
\hline \multirow[b]{2}{*}{ Subject } & \multicolumn{3}{|c|}{ VLDL1 } & \multicolumn{3}{|c|}{ VLDL2 } & \multicolumn{3}{|c|}{ IDL } & \multicolumn{3}{|c|}{ LDL } \\
\hline & $\begin{array}{c}\mathrm{TC} \\
(\mathrm{mmol} / \mathrm{l})\end{array}$ & $\begin{array}{c}\mathrm{TG} \\
(\mathrm{mmol} / \mathrm{l})\end{array}$ & $\begin{array}{c}\text { ApoB } \\
(\mathrm{g} / \mathrm{l})\end{array}$ & $\begin{array}{c}\mathrm{TC} \\
(\mathrm{mmol} / \mathrm{l})\end{array}$ & $\begin{array}{c}\mathrm{TG} \\
(\mathrm{mmol} / \mathrm{l})\end{array}$ & $\begin{array}{c}\text { ApoB } \\
(\mathrm{g} / \mathrm{l})\end{array}$ & $\begin{array}{c}\mathrm{TC} \\
(\mathrm{mmol} / \mathrm{l})\end{array}$ & $\begin{array}{c}\mathrm{TG} \\
(\mathrm{mmol} / \mathrm{l})\end{array}$ & $\begin{array}{c}\text { ApoB } \\
(\mathrm{g} / \mathrm{l})\end{array}$ & $\begin{array}{c}\mathrm{TC} \\
(\mathrm{mmol} / \mathrm{l})\end{array}$ & $\begin{array}{c}\mathrm{TG} \\
(\mathrm{mmol} / \mathrm{l})\end{array}$ & $\begin{array}{c}\text { ApoB } \\
(\mathrm{g} / \mathrm{l})\end{array}$ \\
\hline 1 Base & 0.023 & 1.050 & 0.249 & 0.046 & 0.368 & 0.134 & 0.046 & 0.088 & 0.198 & 0.372 & 0.149 & 0.863 \\
\hline Post & 0.112 & 0.306 & 0.095 & 0.054 & 0.254 & 0.81 .0 & 0.039 & 0.088 & 0.106 & 0.395 & 0.193 & 0.766 \\
\hline 2 Base & 0.015 & 0.569 & 0.269 & 0.008 & 0.289 & 0.138 & 0.012 & 0.026 & 0.026 & 0.352 & 0.193 & 0.526 \\
\hline Post & 0.019 & 0.184 & 0.033 & 0.015 & 0.131 & 0.138 & 0.027 & 0.070 & 0.068 & 0.201 & 0.184 & 0.610 \\
\hline Post & 0.058 & 0.560 & 0.151 & 0.035 & 0.166 & 0.082 & 0.046 & 0.096 & 0.124 & 0.379 & 0.306 & 0.793 \\
\hline 4 Base & 0.097 & 1.041 & 0.233 & 0.043 & 0.245 & 0.112 & 0.039 & 0.070 & $0.21 \cdot 2$ & 0.352 & 0.193 & 0.446 \\
\hline Post & 0.066 & 0.779 & 0.028 & 0.066 & 0.350 & 0.105 & 0.074 & 0.149 & 0.067 & 0.402 & 0.193 & 0.580 \\
\hline 5 Base & 0.074 & $1 \cdot 295$ & 0.237 & 0.039 & 0.324 & 0.128 & 0.039 & 0.079 & $0.57 \cdot 3$ & 0.302 & 0.219 & 0.576 \\
\hline Post & 0.050 & 0.840 & 0.068 & 0.058 & 0.254 & 0.091 & 0.070 & 0.175 & 0.088 & 0.348 & 0.219 & 0.688 \\
\hline \multicolumn{13}{|l|}{ Base } \\
\hline Mean & 0.054 & 1.006 & 0.244 & 0.031 & 0.280 & 0.122 & 0.035 & 0.088 & 0.086 & 0.310 & 0.184 & 0.575 \\
\hline $\mathrm{SD}$ & 0.035 & 0.271 & 0.015 & 0.015 & 0.079 & 0.016 & 0.015 & 0.053 & 0.076 & 0.077 & 0.026 & 0.169 \\
\hline Mean & 0.062 & $0.534^{*}$ & $0.075^{\star *}$ & 0.046 & 0.228 & 0.099 & 0.050 & 0.114 & 0.090 & 0.344 & 0.219 & 0.687 \\
\hline $\mathrm{SD}$ & 0.035 & 0.289 & 0.050 & 0.019 & 0.088 & 0.024 & 0.019 & 0.044 & 0.024 & 0.081 & 0.053 & 0.093 \\
\hline
\end{tabular}

IDL, intermediate-density lipoprotein; TC, total cholesterol; TG, triacylglycerol.

${ }^{\star} P<0.05,{ }^{* \star} P<0.005$.

For details of subjects and procedures, see p. 101.

The effect on LDL apoB100 was variable between subjects (a decrease in one subject and an increase in the others), leading to a slight but not significant increase in LDL apoB100. As shown in Table 1, no effect on BMI, fasting plasma glucose, homeostasis model assessment or $\mathrm{HbA}_{1 \mathrm{c}}$ concentration was observed with treatment.

\section{Lipoprotein kinetics}

The time course of enrichment in VLDL, IDL and LDL apoB100 for subject 3 before and after $n-3$ treatment is shown in Fig. 2. Model fitted lines and experimental points showed close agreement. The masses of B100 calculated by SAAMII in each compartment were also similar to those chemically measured (data not shown). Kinetic parameters are shown in Table 2.

Compared with the basal situation (Table 3), treatment with $n-3$ significantly reduced the overall production of apoB 100 (1.73 (SD 0.28) v. 0.97 (SD 0.13 ) $\mathrm{mg} / \mathrm{kg}$ per $\mathrm{h} ; P<0.05$; Table 2). This decrease was related to VLDL1 apoB100 production (1.49 (SD 0.23) v.0.44 (SD 0.19) $\mathrm{mg} / \mathrm{kg}$ per $\mathrm{h}$; $P<0.05)$. In parallel to this decrease, treatment increased the direct production of IDL (0.02 (SD 0.01) v.0.24 (SD 0.12) $\mathrm{mg} / \mathrm{kg}$ per $\mathrm{h} ; P<0.05$ ) and LDL (0.07 (SD 0.05) v.0.18 (SD $0.17) \mathrm{mg} / \mathrm{kg}$ per $\mathrm{h}$; NS). No effect on the uptake of VLDL was observed with treatment, but the conversion rate was significantly increased (0.031(SD 0.024) v.0.052 (SD 0.04) per h; $P<0.05)$, and VLDL were channelled more towards higherdensity lipoproteins (data not shown). The fractional catabolic rates of IDL and LDL were not affected by the treatment.

\section{Discussion}

The aim of the present study was to examine, in type 2 diabetes, the effect of $n-3$ fatty acids $(1.8 \mathrm{~g} / \mathrm{d})$ on the metabolism of apoB100-containing lipoprotein. Analyses were performed using stable isotopes on fasting subjects to avoid any acute influence of $n$-3-containing chylomicrons and chylomicron remnants on apoB100 metabolism. The model used in this study includes heterogeneity of VLDL and is consistent, as shown by the low $\mathrm{CV}$ of parameters. The present study showed that, in type 2 diabetes, $n-3$ fatty acids lowered triacylglycerolaemia by decreasing apoB100 VLDL production and by stimulating VLDL conversion to IDL. The heterogeneous response to $n-3$ fatty acids led to a non-significant increase
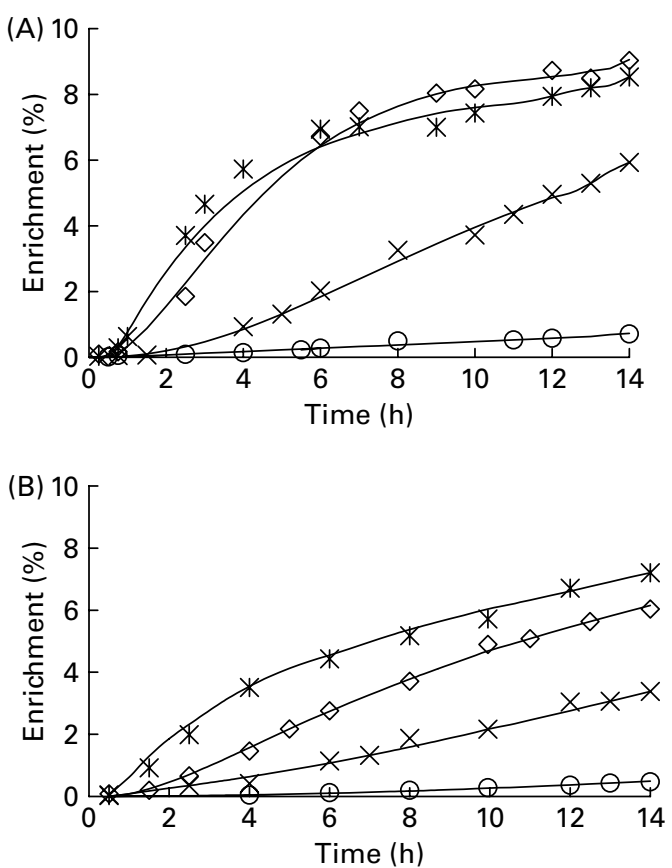

Fig. 2. Time course of enrichment of VLDL $1(\diamond)$, VLDL $2(\mathbb{X})$, intermediatedensity lipoprotein $(X)$ and $L D L(O)$ apoB100 in a representative diabetic subject (number 3 ) before $(A)$ and after $(B)$ supplementation with MaxEPA (Pierre Fabre Santé, Castres, France). For details of subjects and procedures, see p. 101. 
of LDL in spite of a higher conversion rate of VLDL and a non-significant increase of direct LDL production. Treatment with $n-3$ acids did not affect diabetic control.

In type 2 diabetic patients, the kinetics of apoB100 metabolism is well documented (Duvillard et al. 2000; Ouguerram et al. 2003). Briefly, in mild diabetes, an overproduction of VLDL and impaired lipolysis leads to hypertriacylglycerolaemia (Duvillard et al. 2000), whereas in moderate or severe diabetes, a delay in LDL catabolism is also reported, explaining the combined hyperlipidaemia (Kissebah et al. 1983; Ouguerram et al. 2003).

The present study is the first kinetic study on diabetic subjects performed in the fasting state that has compared the effect of $n-3$ fatty acid treatment to a basal diet. To distinguish a chronic effect of $n-3$ fatty acids and an acute effect of $n-3$ absorption, the study was performed in the fasting state, in contrast to a previous study by Fisher et al. (1998). It is well known that chylomicrons and their remnants enriched in $n-3$ fatty acids (Zheng et al. 2001; Maldonado et al. 2003) or a direct delivery of dietary $n$-3 PUFA to the liver (Wang et al. 1993) reduces hepatic VLDL synthesis. A study design performed in the feeding state did not allow a discrimination between a short-term effect consequent on absorptive flux and a long-term effect consequent on a change in cell membrane composition. To avoid such confusion, the present kinetic study was conducted in the fasting state.

The effect of fish oil on plasma lipid and apo concentration has been well documented in animal (Harris, 1996) and in healthy (Connor et al. 1993) and hypertriacylglycerolaemia (Fisher et al. 1998; Chan et al. 2003) human subjects. In these studies, dramatic reductions in plasma triacylglycerol levels occurred, with an inconsistent response in plasma total cholesterol that varied from study to study depending on the diet previously administrated and mainly with the nature of the fatty acids added, although also with the dose administered and the duration of treatment (Fisher et al. 1998; Farmer et al. 2001). The mechanisms underlying these effects were largely reported in animals (Harris, 1996), and healthy human subjects (Connor et al. 1993; Harris, 1996), but data on diabetic subjects have been missing, particularly in terms of the lack of a kinetic study. Only one study had previously been performed on diabetic subjects (Fisher et al. 1998), but the data compared $n-6$ and $n-3$ treatments without making any comparison with the basal state.

In the present study, $n-3$ acids significantly decreased triacylglycerolaemia. This fall is related to lower VLDL and especially VLDL1 production, as previously reported in other studies (Fisher et al. 1998; Chan et al. 2003). This was not related to a change in the abundance of mRNA for apoB100 (Zheng et al. 2001). However, an enhanced intracellular degradation of apoB100 was shown in primary rat hepatocytes (Wang et al. 1993). One other major effect of $n-3$ is the inhibition of triacylglycerol synthesis by decreasing the activity of acyl-CoA:1.2-diacylglycerol acyltransferase (Rustan et al. 1988) and increasing their triacylglycerol oxidation (Yamazaki et al. 1987). Several studies have also showed that $n$-3 fatty acids regulate the expression of numerous genes (Clarke, 2004) involved in the suppression of fatty acid synthesis. As VLDL secretion depends on the available synthesised triacylglycerol (Wu et al. 1996), the inhibition of fatty acid and triacylglycerol synthesis could result in an increased degradation of apoB100. It also has to be emphasised that the present study was performed in the fasting

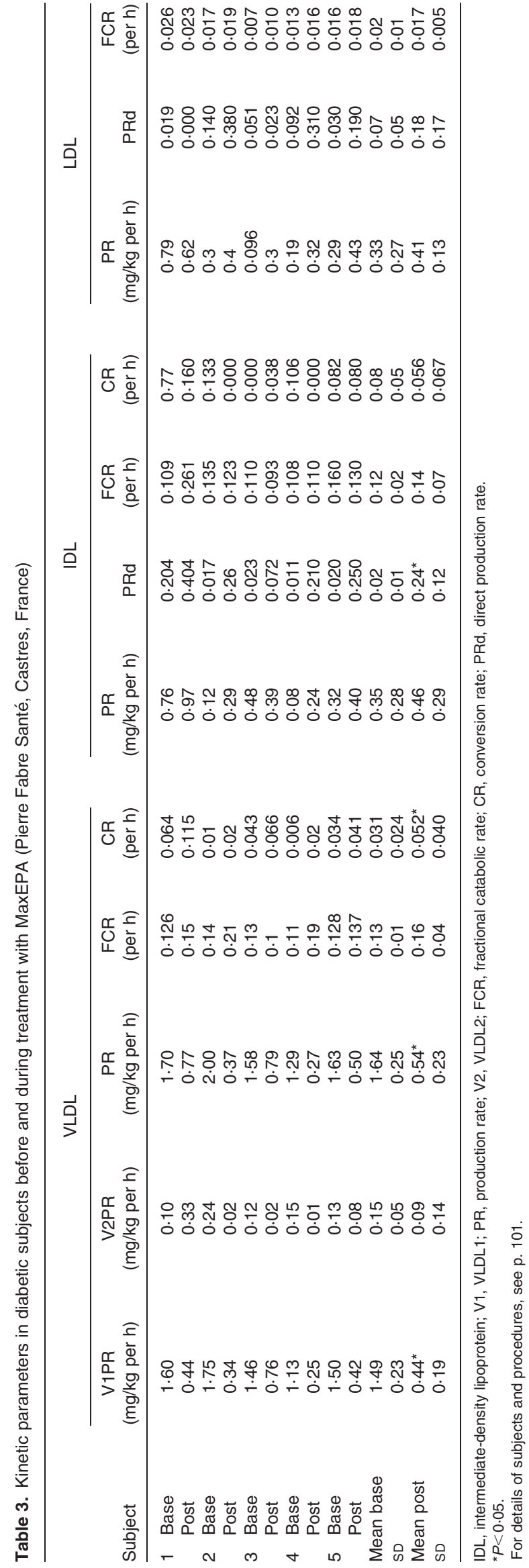


state, suggesting that VLDL synthesis was not due to an acute inhibition by $n$-3-enriched chylomicrons but probably to profound and chronic changes in $n-3$ concentration in the hepatocytes after long-term treatment.

We did not observe any effect of $n-3$ fatty acids on the VLDL, IDL and LDL fractional catabolic rates. Although the absence of a significant effect on VLDL and IDL fractional catabolic rate has previously been reported (Fisher et al. 1998; Chan et al. 2003), data on the LDL fractional catabolic rate are conflicting (Ventura et al. 1989; Spady et al. 1995; Schectman et al. 1996; Vasandani et al. 2002; Theobald et al. 2004). Feeding fish oil stimulated the clearance of LDL in rats (Ventura et al. 1989) and mice (Vasandani et al. 2002) but decreased the receptor-mediated clearance of LDL in hamsters (Spady et al. 1995), primates (Schectman et al. 1996) and human subjects (Theobald et al. 2004). This decrease could be a result of either decreased binding of LDL to the LDL receptor or decreased expression of the LDL receptor. The decrease in the number of specific binding sites for acetyl LDL in peritoneal macrophages in rat by EPA was reported by Saito et al. (1992). LDL undergo a change in physical properties in response to $n-3$ fatty acids (Bell et al. 1996), which renders them more susceptible to oxidation (Whitman et al. 1994; Nestel et al. 1997). Although LDL generated after $n-3$ supplementation are susceptible to oxidation (Whitman et al. 1994; Nestel et al. 1997), they are not atherogenic. In the present study, as in others (Fisher et al. 1998), LDL have been analysed as a one homogenous pool, so the fractional catabolic rate measured is a mean of that for all LDL subpopulations. Although Rivellese et al. (2003) observed no modification in LDL size on $n-3$ supplementation, it might be interesting to examine their effect on the kinetics of small and large LDL.

In the present study, we showed that $n-3$ fatty acids increased the conversion of VLDL to IDL but not the conversion of IDL to LDL. The effect of $n-3$ fatty acids on lipoprotein lipase (LPL) activity was reported in animals (Huff \& Telford, 1989), healthy human subjects (Kasim-Karakas et al. 1995; Harris et al. 1997) or insulin-resistant human subjects (Chan et al. 2003). Dietary $n-3$ fatty acids have been also shown to accelerate chylomicron triacylglycerol clearance in rats (Rahman et al. 2000). Supplementation with $n$ - 3 enhances chylomicron triacylglycerol clearance by increasing LPL and hepatic lipase activity in healthy subjects but only LPL activity in hypertriacylglycerolaemia patients (Harris et al. 1997). An increase in post-heparin LPL activity and the level of LPL mRNA in the adipose tissue of subjects with an atherogenic lipoprotein phenotype has been reported with $n-3$ acids (Khan et al. 2002). In parallel to a decrease of VLDL production, $n-3$ fatty acids shift the channelling of apoB100 from large VLDL to small VLDL, IDL and LDL. This could be explained by the secretion of small VLDL with a lower triacylglycerol:apoB ratio, which are rapidly converted to LDL (Lu et al. 1999).

In the present study, we did not observe any difference in the triacylglycerol:apoB ratio between the two states (data not shown). This discrepancy could be explained by the lower dose of $n$-3 used in our study. In Fisher et al.'s (1998) study, the authors did not observe any change in lipoprotein conversion. In that study, the comparison was against a diet enriched in $n-6$ fatty acids, and any comparison with a basal diet was missing. Although the major effect of $n-6$ fatty acids is to lower plasma cholesterol level (Kasim-Karakas et al. 1995), they also increase plasma triacylglycerol hydrolysis as $n-3$ fatty acids (Mekki et al. 2002). Therefore, the comparison between $n-3$ and $n-6$ fatty acids does not allow an assessment of the actual magnitude of the effect of $n-3$. Because $n-3$ fatty acids affect VLDL conversion into IDL, but not the conversion of IDL into LDL, we suggest that LPL and hepatic lipase are not regulated by similar pathways (Peinado-Onsurbe et al. 1992; Ouguerram et al. 2003).

In conclusion, $n-3$ fatty acids were effective in lowering triacylglycerolaemia in individuals with type 2 diabetes patients via the suppression of VLDL production and the stimulation of its conversion into LDL. As diabetic subjects also respond to statins known to stimulate LDL uptake (Ouguerram et al. 2003), combined therapy could be recommended in case of mixed dyslipidaemia.

\section{Acknowledgements}

This work was supported by Pierre Fabre Santé. The authors are grateful to Carole Le Valegant for her technical assistance.

\section{References}

Austin MA \& Hokanson JE (1994) Epidemiology of triglycerides, small dense low-density lipoprotein, and lipoprotein (a) as risk factors for coronary heart disease. Med Clin North Am 78, 99-115.

Beghin L, Duhal N, Poulain P, Hauw P, Lacroix B, Lecerf JM, Bonte JP, Fruchart JC \& Luc G (2000) Measurement of apoB concentration in plasma lipoproteins by combining selective precipitation and mass spectrometry. J Lipid Res 41, 1172-1176.

Bell JD, Barnard ML, Parkes HG, Thomas EL, Brennan CH, Cunnane SC \& Dagnelie PC (1996) Effects of n-3 fatty acids on the NMR profile of plasma lipoproteins. J Lipid Res 37, 1664-1674.

Brown ML, Ramprasad MP, Umeda PK, et al. (2000) A macrophage receptor for apolipoprotein B48: cloning, expression, and atherosclerosis. Proc Natl Acad Sci 97, 7488-7493.

Chan DC, Watts GF, Mori TA, Barrett PH, Redgrave TG \& Beilin LJ (2003) Randomized controlled trial of the effect of n-3 fatty acid supplementation on the metabolism of apolipoprotein B-100 and chylomicron remnants in men with visceral obesity. Am J Clin Nutr 77, 300-307.

Clarke SD (2004) The multi-dimensional regulation of gene expression by fatty acids: polyunsaturated fats as nutrient sensors. Curr Opin Lipidol 15, 13-18.

Cobelli C, Toffolo G \& Foster DM (1992) Tracer-to-tracee ratio for analysis of stable isotope trace data: link with radioactive kinetic formalism. Am J Physiol 262, E968-E975.

Connor WE, Defransesco CA \& Connor SL (1993) N-3 fatty acids from fish oil: effects on plasma lipoproteins and hypertriglyceridemic patients. Ann N Y Acad Sci 683, 16-34.

Dagher FJ, Lyons JH, Finlayson DC, Shamsai J \& Moore FD (1965) Blood volume measurement: critical study. Prediction of normal values, controlled measurement of sequential changes, choice of a bedside method. Adv Surg 1, 69-109.

Duvillard L, Pont F, Florentin E, Galland-Jos C, Gambert P \& Verges B (2000) Metabolic abnormalities of apolipoprotein B-containing lipoproteins in non-insulin-dependent diabetes: a stable isotope kinetic study. Eur J Clin Invest 30, 685-694.

Farmer A, Montori V, Dinneen S \& Clar C (2001) Fish oil in people with type 2 diabetes mellitus. Cochrane Database Syst Rev 3, CD003205. 
Fielding CJ, Vlodavsky I, Fielding PE \& Gospodarowicz D (1979) Characteristics of chylomicron binding and lipid uptake by endothelial cells in culture. J Biol Chem 254, 8861-8868.

Fisher WR, Zech LA \& Stacpoole PW (1998) Apolipoprotein B metabolism in hypertriglyceridemic diabetic patients administered either a fish oil- or vegetable oil-enriched diet. J Lipid Res 39, 388-401.

Gianturco SH, Eskin SH, Navarro LT, Lahart CJ, Smith LC \& Gotto AM Jr (1980) Abnormal effects of hypertriacylglycerolemic very low-density lipoproteins on 3-hydroxy-3-methylglutaryl-CoA reductase activity and viability of cultured bovine aortic endothelial cells. Biochim Biophys Acta 618, 143-152.

Goldberg IJ (2001) Diabetic dyslipidemia: causes and consequences. $J$ Clin Endocrin Metab 86, 965-971.

Harris WS (1996) n-3 fatty acids and lipoproteins: comparison of results from human and animals studies. Lipids 31, 246-252.

Harris WS, Lu G, Rambjor GS, Walen AI, Ontko JA, Cheng Q \& Windsor SL (1997) Influence of n-3 fatty acid supplementation on the endogenous activities of plasma lipases. Am J Clin Nutr 66, 254-260.

Huff MW \& Telford DE (1989) Dietary fish oil increases conversion of very low density lipoprotein apoprotein B to low density lipoprotein. Arteriosclerosis 9, 58-66.

Kannel WB, Castelli WP, Cordon T \& McNamara PM (1971) Serum cholesterol, lipoproteins, and the risk of coronary heart disease: the Framingham Study. Ann Intern Med 74, 1-12.

Kasim-Karakas SE, Herrmann R \& Almario R (1995) Effects of omega-3 fatty acids on intravascular lipolysis of very-low-density lipoproteins in humans. Metabolism 44, 1223-1230.

Kissebah AH, Alfarsi S, Evans DJ \& Adams PW (1983) Plasma low density lipoprotein transport kinetics in noninsulin-dependent diabetes mellitus. J Clin Invest 71, 655-667.

Khan S, Minihane AM, Talmud PJ, Wright JW, Murphy MC, Williams CM \& Griffin BA (2002) Dietary long-chain n-3 PUFAs increase LPL gene expression in adipose tissue of subjects with an atherogenic lipoprotein phenotype. J Lipid Res 43, 979-985.

Kromann N \& Green A (1980) Epidemiological studies in the Upernavik district, Greenland incidence of some chronic diseases 1950-1974. Acta Med Scand 208, 401-406.

Lichtenstein AH, Kennedy E, Barrier P, Danford D, Ernst ND, Grundy SM, Leveille GA, Van Horn L, Williams CL \& Booth SL (1998) Dietary fat consumption and health. Nutr Rev 56, S3-S19, discussion S19-S28.

Lu G, Windsor SL \& Harris WS (1999) Omega-3 fatty acids alter lipoprotein subfraction distributions and the in vitro conversion of very low density lipoproteins to low density lipoproteins. J Nutr Biochem 10, 151-158.

Maldonado EN, Chico Y, Botham KM, Aveldano MI \& Ochoa B (2003) Influence of the fatty acid composition of lipids in chylomicron remnants derived from fish or corn oil on the lipid profile of cultured rat hepatocytes. J Physiol Biochem 59, 85-100.

Matthews DR, Hosker JP, Rudenski AS, Naylor BA, Treacher DF \& Turner RC (1985) Homeostasis model assessment: insulin resistance and beta-cell function from fasting glucose and insulin concentrations in man. Diabetologia 28, 412-419.

Mekki N, Charbonnier M, Borel P, Leonardi J, Juhel C, Portugal H \& Lairon D (2002) Butter differs from olive oil and sunflower oil in its effects on postprandial lipemia and triacylglycerol-rich lipoproteins after single mixed meals in healthy young men. J Nutr 132, 3642-3649.

Nestel PJ, Pomeroy SE, Sasahara T, Yamashita T, Liang YL, Dart AM, Jennings GL, Abbey M \& Cameron JD (1997) Arterial compliance in obese subjects is improved with dietary plant n-3 fatty acid from flaxseed oil despite increased LDL oxidizability. Arterioscler Thromb Vasc Biol 17, 1163-1170.

Ouguerram K, Magot T, Zair Y, Marchini JS, Charbonnel B, Laouenan H \& Krempf M (2003) Effect of atorvastatin on apolipoprotein B100 containing lipoprotein metabolism in type-2 diabetes. J Pharm Exp Ther 306, 332-337.
Peinado-Onsurbe J, Soler C, Soley M, Llobera M \& Ramirez I (1992) Lipoprotein lipase and hepatic lipase activities are differentially regulated in isolated hepatocytes from neonatal rats. Biochem Biophys Acta 1125, 82-89.

Pont F, Duvillard L, Verges B \& Gambert P (1998) Development of compartmental models in stable isotope experiments. Application to lipid metabolism. Arterioscler Thromb Vasc Biol 8, 853-860.

Rahman MH, Avella MA \& Botham KM (2000) The fatty acid composition of chylomicrons influences the rate of their lipolysis in vivo. Nutr Metab Cardiovasc Dis 10, 121-125.

Rivellese AA, Maffettone A, Vessby B, Uusitupa M, Hermansen K, Berglund L, Louheranta A, Meyer BJ \& Riccardi G (2003) Effects of dietary saturated, monounsaturated and n-3 fatty acids on fasting lipoproteins, LDL size and post-prandial lipid metabolism in healthy subjects. Atherosclerosis 167, 149-158.

Rustan AC, Nossen JO, Christiansen EN \& Drevon CA (1988) Eicosapentanenoic acid reduces hepatic synthesis and secretion of triacylglycerol by decreasing the activity of acyl-CoA: 1.2-diacylglycerol acyltransferase. J Lipid Res 29, 1417-1426.

Saito I, Saito H, Tamura Y \& Yoshida S (1992) Eicosapentaenoic acid inhibits cholesteryl ester accumulation in rat peritoneal macrophages by decreasing the number of specific binding sites of acetyl LDL. Clin Biochem 25, 351-355.

Schectman G, Boerboom LE, Hannah J, Howard BV, Mueller RA \& Kissebah AH (1996) Dietary fish oil decreases low-density-lipoprotein clearance in nonhuman primates. Am J Clin Nutr 64, 215-221.

Spady DK, Horton JD \& Cuthbert JA (1995) Regulatory effects of n3 polyunsaturated fatty acids on hepatic LDL uptake in the hamster and rat. J Lipid Res 36, 1009-1020.

Theobald HE, Chowienczyk PJ, Whittall R, Humphries SE \& Sanders TA (2004) LDL cholesterol-raising effect of low-dose docosahexaenoic acid in middle-aged men and women. Am J Clin Nutr 79, 558-563.

Vasandani C, Kafrouni AI, Caronna A, Bashmakov Y, Gotthardt M, Horton JD \& Spady DK (2002) Upregulation of hepatic LDL transport by n-3 fatty acids in LDL receptor knockout mice. J Lipid Res 43, 772-784.

Ventura MA, Woollet LA \& Spady DK (1989) Dietary fish oil stimulate hepatic low density lipoprotein transport in the rat. $J$ Clin Invest 84, 528-537.

Wang HX, Chen X \& Fisher EA (1993) N-3 fatty acids stimulate intracellular degradation of apoprotein $\mathrm{B}$ in rat hepatocytes. J Clin Invest 91, 1380-1389.

Whitman SC, Fish JR, Rand ML \& Rogers KA (1994) n-3 fatty acid incorporation into LDL particles renders them more susceptible to oxidation in vitro but not necessarily more atherogenic in vivo. Arterioscler Thromb 14, 1170-1176.

Wu X, Shang A, Jiang H \& Ginsberg HN (1996) Low rates of apoB secretion from HepG2 cells result from reduced delivery of newly synthesized triglyceride to a "secretion-coupled" pool. J Lipid Res 37, 1198-1206.

Yamazaki RK, Shen T \& Schade GB (1987) A diet rich in (n-3) fatty acids increases peroxisomal beta-oxidation activity and lowers plasma triacylglycerols without inhibiting glutathione-dependent detoxication activities in the rat liver. Biochim Biophys Acta 920 , $62-67$.

Zheng X, Avella M \& Botham KM (2001) Comparison of the effects of dietary n-3 and n-6 polyunsaturated fatty acids on very-low-density lipoprotein secretion when delivered to hepatocytes in chylomicron remnants. Biochem J 357, 481-487.

Zheng X, Rivabene R, Cavallari C, Napolitano M, Avella M, Bravo E \& Botham KM (2002) The effects of chylomicron remnants enriched in n-3 or n- 6 polyunsaturated fatty acids on the transcription of genes regulating their uptake and metabolism by the liver: influence of cellular oxidative state. Free Radic Biol Med 32, 1123-1131.

Zilversmit DB (1979) Atherogenesis: a postprandial phenomenon. Circulation 60, 473-485. 